H. FERIZ

\title{
EEN MERKWAARDIGE STENEN KRAAL UIT SURINAME
}

In september 1959 ontving ik van de Heer G. Findlay, Paramaribo, de fotografie van een stenen kraal, die in het kustgebied van het district Marowijne door een Indiaan bij of in een door een gordeldier gegraven hol werd gevonden. De in beide kanten van deze kraal gegraveerde tekening (fig. I) is zeer ongewoon en herinnert stilistisch aan afbeeldingen uit het Sumerische en Egyptische cultuurgebied. Het object - dat niet zelf kon worden onderzocht - is, dunkt mij, van voldoende interesse om in dit tijdschrift te bespreken.

De kraal is plat, ovoied, overlangs doorboord en meet $27: 25$ : $5 \mathrm{~mm}$. Het materiaal is licht groenachtig blauw, doorschijnende steen of glas; aan de voor- en achterzijde is een menselijk gelaat gegraveerd, omgeven door een hoefijzervormige hoofdtooi, die aan een gestileerde tweekoppige slang herinnert, een in de iconographie van Centraal- en Zuid-Amerika zeer verspreid symbool van het leven en de vruchtbaarheid. Toch maakt de tekening op het eerste gezicht bepaald geen Indiaanse indruk. De fijn gegraveerde, vloeiend gebogen omlijsting van het driehoekige gelaat, de kleine, smalle mond, de ovale, horizontaal staande ogen, de licht-concave begrenzing van de orbita, overgaande in de contour van de rechte, aan de punt iets verbrede neus, herinneren aan voorbeelden uit de Oude Wereld. Daarbij komt, dat de het hoofd hoefijzervormig omsluitende tooi, die op een slang lijkt met een kop aan elk uiteinde, overeenkomt met het kapsel op de beelden van de oud-Egyptische en Phoenicische vruchtbaarheidsgodin Hathor (fig. 2-4, ontleend aan BARB), waarvan de vorm klaarblijkelijk geïnspireerd is door die van het reeds in de Sumerische cultuur conventionele teken van de baarmoeder (fig. 4, ontleend aan BARB). Dit 'hoefijzer', dat veelvuldig in koeienhorens getransformeerd werd, bleef in het gebied van de Middellandse Zee tevens een symbool van de maansikkel en als zodanig eveneens 
vrouwelijk gedetermineerd. De schubben op het lichaam van de slang (fig. 2), de schelpen en de spiralen wijzen op de verbondenheid van de godin met het water - eveneens een symbool van leven en vruchtbaarheid. De figuren op de afbeeldingen 3 en 5 vertonen op de plaats van de spiralen aan de uiteinden, waar men de koppen van de slang vermoedt, cirkels met een centraal geplaatst 'oog'. De betekenis van de dwarse strepen op het slangenlichaam van fig. 3 is onduidelijk. De boven het hoofd divergerende lijnen kunnen stralen voorstellen en tezamen met het cirkelsegment op het voorhoofd op de siderische-lunaire geaardheid van de godin duiden. Op de stenen kraal van de Marowijne zien wij deze divergerende strepen als uitsteeksels van een platte, driehoekige kap, die door haar licht gebogen contouren aan een maansikkel doet denken. Evenals de tweekoppige slang komt de conische hoofdbedekking op oud-Indiaanse beelden vaak voor. Zij wordt algemeen als een teken van de rang van de drager beschouwd. Bij de Indianen van de noordwestkust van Amerika, in Costa Rica, Panamá en Colombia werden de stamhoofden met conische hoofdbedekkingen afgebeeld; goden en voorouders dragen soms twee of drie soortgelijke hoeden boven elkaar. Op de beschilderde keramiek van Nasca (Zuid-Perú) is de conische hoofdbedekking een attribuut van een met de vruchtbaarheid van de aarde verband houdend, bovennatuurlijk schepsel.

Het is niet twijfelachtig, dat de conische hoed als teken van rang en waardigheid van de Oude Wereld en wel van Oost-Azië afkomstig is. Wij kunnen echter nauwelijks veronderstellen, dat de eerste primitieve immigranten, die Amerika in de laatste ijstijd van Noordoost-Azië uit bereikten, dit rangteken reeds kenden. Het behoort immers bij een gevorderde sociale structuur en een hogere materiële cultuur. Derhalve mogen wij in deze hoofdbedekking een aanwijzing te meer zien voor een later contact tussen Azië en Amerika. Hoe dan ook: noch de hoofdbedekking, noch de dubbele slang pleit tegen de Indiaanse oorsprong van het object, dat in Suriname gevonden werd. Wij behoeven dus ondanks de stilistische overeenkomsten met oud-Egyptische voorwerpen geenszins aan een transatlantische import te denken, die weliswaar a priori niet uit te sluiten is wegens het feit, dat de van Noord-Afrika naar de noordelijke Guyanakust verlopende Noord-Passaatstroom dit mogelijk gemaakt zou kunnen hebben.

Het Atlantisprobleem is niet opgelost en tot nu toe kon geen enkele aanwijzing voor praehistorische of vroeghistorische contacten tussen de Oude Wereld en Zuid-Amerika de toets van de 
wetenschappelijke kritiek doorstaan. Ook de merkwaardige tekening op de stenen kraal is niet als een dergelijke aanwijzing te beschouwen, gezien de parallellen in de oud-Indiaanse kunstnijverheid. Vooral dient opgemerkt te worden, dat een haartooi die het gezicht als een hoefijzer omsluit, bij vele Zuidamerikaanse Indianenstammen, vooral bij die uit het Amazonegebied, reeds in de oudste tijden gebruikelijk was. Wij zien deze haartooi, die thans nog gedragen wordt, reeds bij de klei-figuurtjes van de 4000-4500 jaar oude archaïsche cultuur van San Pablo en Valdivia in Ecuador (fig. 6 en 7 volgens Evans, MEgGers \& EstraDA). Fig. 6 vertoont bovendien een sagittale streepvormige tonsuur, die schijnt overeen te komen met de vertikale band boven de neuswortel op fig. 2 en 3. Ook op jongere Indiaanse amuletten wordt de slang met twee koppen herhaaldelijk als hoofdtooi gevonden, vooral in Colombia en Panamá. Grote overeenkomst met de stenen kraal van de Marowijne vertonen de oorsieraden uit donkergrijze steen, die in het Museo Municipal in Guayaquil bewaard worden. Ze stammen van de Ecuadoriaanse provincie Manabi. De gegraveerde tekening stelt een menselijk gelaat voor, dat door een gestileerde slang met twee koppen hoefijzervormig omsloten wordt. Zoals op fig. 3 worden de koppen van deze slang door cirkelvormige verdikkingen aan de uiteinden met centrale 'ogen' aangeduid. Deze paralellen lijken mij bijzonder belangrijk, omdat ik in de culturen van de centrale kust van Ecuador, die tot in het Amerikaanse archaïcum teruggaan, de wortels van de Amazone-Indianenculturen vermoed, waaruit de Surinaamse culturen zijn voortgekomen. Het is een bekend feit, dat tot in de koloniale tijd handelsverbindingen bestonden tussen de middenloop van de Amazonas en Suriname. Vooral de aan de Rio Tapajoz wonende stammen, die vaardige steenbewerkers waren, hebben de produkten van hun kunstnijverheid in het Noorden verhandeld. Kleinplastieken uit Amazoniet-steen, die van deze streek afkomstig zijn, werden herhaaldelijk in Suriname gevonden. Ook in de rijke collectie van de Heer Findlay bevinden zich enkele van de Rio Tapajoz afkomstige objecten die in mijn reisverslag Suriname zijn afgebeeld en beschreven.

Het lijkt mij dan ook het meest waarschijnlijk, dat de hier beschreven stenen kraal eveneens een importstuk uit het gebied van de Rio Tapajoz is. 

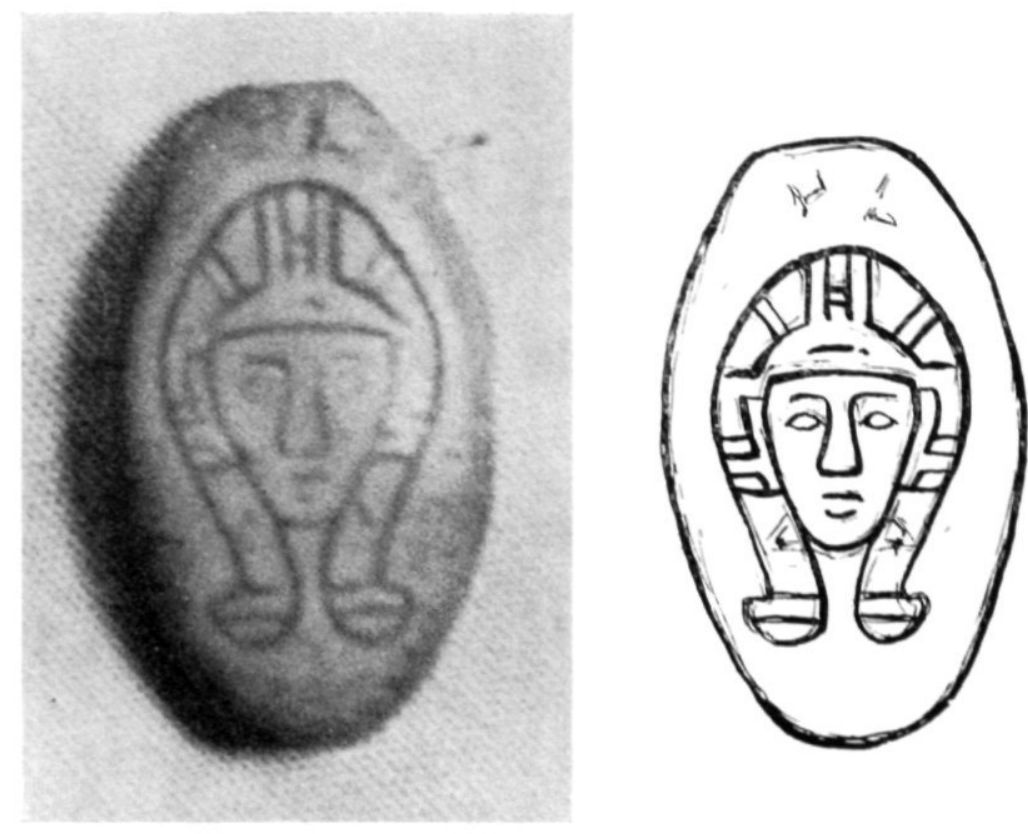

Fig. I-Ia. Stenen kraal uit de collectie Findeay, gevonden in het kustgebied van het district Marowijne, met gegraveerde tekening.
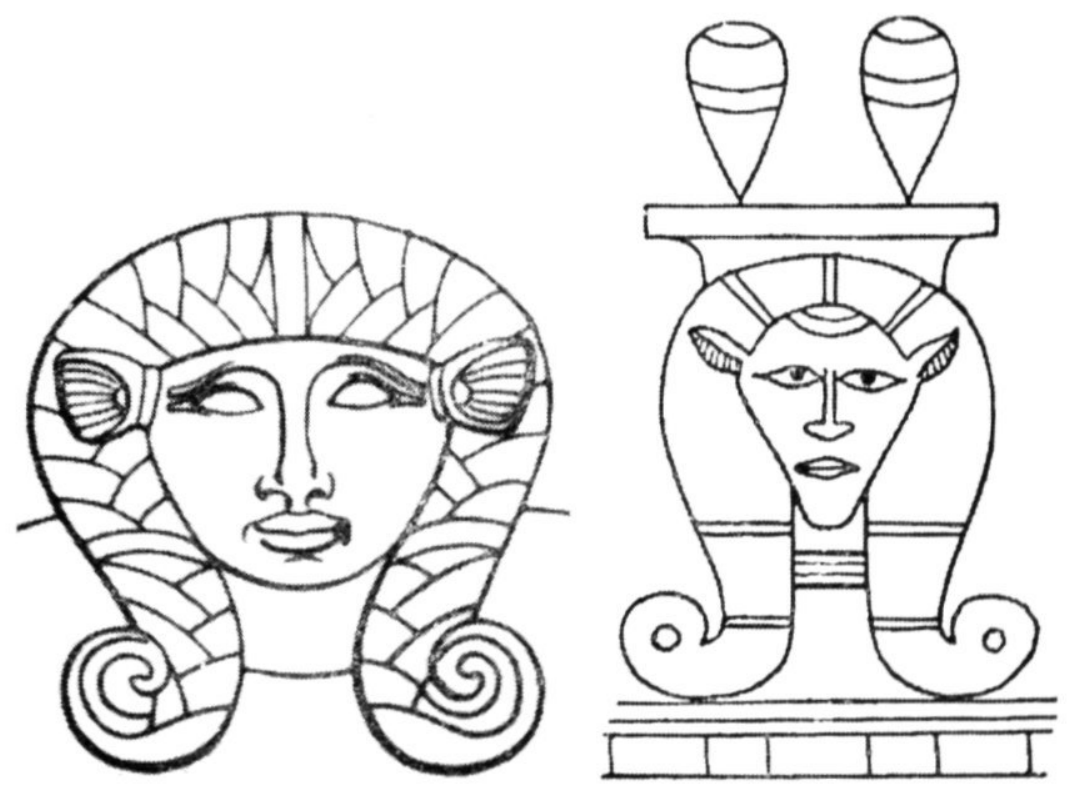

Fig. 2-3. Beelden van de oud-Egyptische en Phoenicische vruchtbaarheidsgodin Hathor (ontleend aan BARB, 1933). Bespreking in de tekst. 

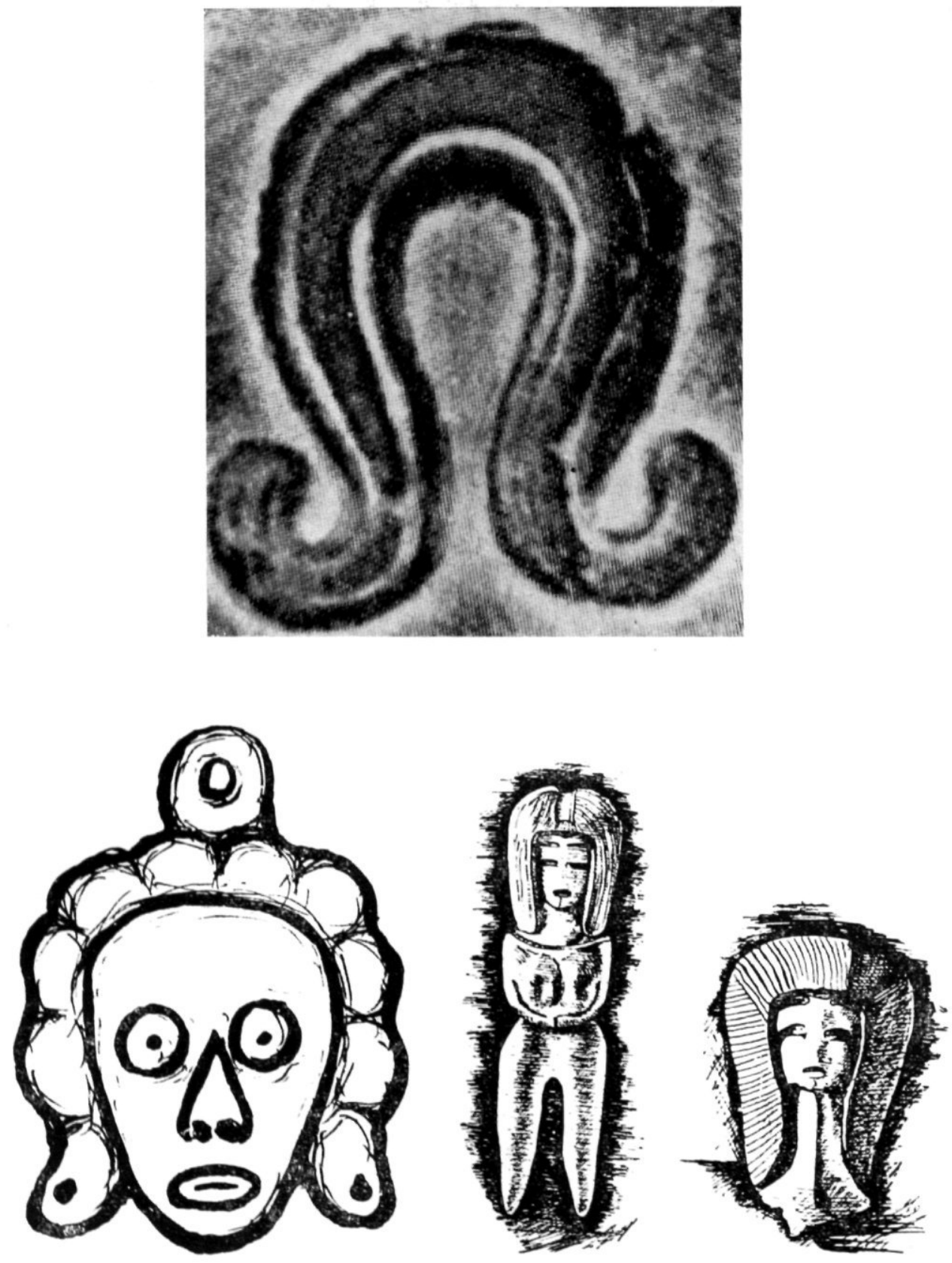

Fig. 4-5. Beelden van de oud-Egyptische en Phoenicische vruchtbaarheidsgodin Hathor (ontleend aan BARB, 1933). Bespreking in de tekst. Fig. 6-7. Klei-figuurtjes van de archaïsche cultuur in Ecuador (volgens Evans, Meggers \& Estrada, r959). Bespreking in de tekst. 
EEN MERKWAARDIGE STENE

wetenschappelijke kritiek door

NIEUWE WEST-INDISCHE GIDS 42ste Jaargang, No. 3, Mei I963

\section{ERRATA}

De onderschriften van Fig. 4-5 tegenover blz. 257 moeten luiden:

Fig. 4 (boven). Hoefijzervormig vruchtbaarheidssymbool op een Babylonische grenssteen (volgens BARB, 1933).

Fig. 5 (links-onder). Oorsieraad uit Manabi, Ecuador (naar een schets door de schrijver).

Op bladzijde 255, regel 6 van onder, leze men 'fig. 2-3', in plaats van 'fig. 2-4'; op bladzijde 257 , regel 19, voege men in achter 'tekening': (fig. 5).

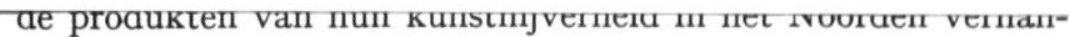
deld. Kleinplastieken uit Amazoniet-steen, die van deze streek afkomstig zijn, werden herhaaldelijk in Suriname gevonden. Ook in de rijke collectie van de Heer FINDLAY bevinden zich enkele van de Rio Tapajoz afkomstige objecten die in mijn reisverslag Suriname zijn afgebeeld en beschreven.

Het lijkt mij dan ook het meest waarschijnlijk, dat de hier beschreven stenen kraal eveneens een importstuk uit het gebied van de Rio Tapajoz is. 


\section{EEN MERKWAARDIGE STENEN KRAAL UIT SURINAME}

In augustus 1962 heeft de Heer Findlay mij, bij het 35 e Internationale Amerikanistencongres in Mexico de beschreven kraal getoond. De vraag naar de oorsprong van dit object zou slechts door een wetenschappelijk onderzoek van het materiaal (dat op Egyptisch glas geleek) te beantwoorden zijn.

\section{LITERATUUR}

BARB, A. A.: Diva Matrix. Journal of the Warburg \& Courtauld Institutes 16 , London, 1933, p. 193-238.

Evans, Cl. \& Meggers, B. \& Estrada, E.: Cultura Valdivia. Museo E. Estrada, Guayaquil, 1959.

Feriz, H.: Suriname. Kon. Instituut v.d. Tropen, Amsterdam, 1957.

Zevallos Menendez, C. \& Holm, O.: Excavationes arqueológicas en San Pablo. Casa de la Cultura, Guayaquil, r96o.

\section{SUMMARY}

A REMARKABLE STONE BEAD FROM SURINAM

The photograph of a stone bead, found in the coastal area of Marowijne District, Surinam, and now in the collection of G. FINDLAY, Paramaribo, is discussed. The picture engraved on both sides of this bead (Fig. I) is very unusual, and is reminiscent in style of representations from the Sumerian and Egyptian cultural region. The writer considers it probable that the bead was imported from the area of the Rio Tapajoz, Brazil. 